\title{
Construção de um Instrumento para Avaliar o Uso de Bebidas Alcóolicas em uma Etnia Indígena de Minas Gerais
}

\author{
Ronaldo Santhiago Bonfim de Souza ${ }^{1}$ \\ Júlia Costa de Oliveira ${ }^{2}$ \\ ${ }^{1}$ Universidade Federal de Minas Gerais, MG, Brasil. \\ ${ }^{2}$ Universidade Federal de Minas Gerais, MG, Brasil. \\ Maycoln Leôni Martins Teodoro ${ }^{3}$ \\ ${ }^{3}$ Universidade Federal de Minas Gerais, MG, Brasil.
}

\begin{abstract}
Resumo: O uso abusivo de bebidas alcoólicas é um grave problema de saúde pública em indígenas brasileiros. O objetivo deste estudo foi desenvolver uma entrevista de avaliação que entendesse a frequência do uso e os prejuízos do álcool nessas comunidades, e utilizá-la em uma avaliação inicial. Tal entrevista de avaliação foi desenvolvido a partir de uma revisão sistemática de instrumentos já utilizados nacional e internacionalmente. No estudo piloto, seis lideranças indígenas foram avaliadas por entrevistas individuais, que foram submetidas à análise de conteúdo e categorização das respostas. Dos indígenas avaliados, todos relataram ter consumido bebida alcoólica, três apresentaram comportamentos de beber muito e dois reconheceram a necessidade de buscar tratamento para seu consumo de bebida. Os resultados encontrados demonstram ser possível avançar na avaliação do uso de álcool em indígenas no Brasil. O aperfeiçoamento da avaliação desenvolvida possibilitará a elaboração de projetos de intervenção adequados para o enfrentamento do abuso de álcool nas comunidades indígenas. A Psicologia, de forma técnica e ética, deve estar presente nessa problemática, cara às necessidades biopsicossociais dessas populações.
\end{abstract}

Palavras-chave: Avaliação em Saúde, Alcoolismo, População Indígena.

\section{Construction of an Instrument to Evaluate the Use of Alcoholic Beverages in an Indigenous Ethnic Group of Minas Gerais}

\begin{abstract}
The alcohol abuse represents a serious public health problem in Brazilian indigenous groups. The aim of this research is to develop an interview to evaluate alcohol use, seeking to understand its frequency and damages in indigenous communities, making an initial evaluation. This evaluation interview was developed from a systematic review of instruments already used nationally and internationally. In the pilot study, six indigenous leaders were evaluated by individual interviews, which were subjected to content analysis and categorization of answers. It was found that all evaluated indigenous leaders reported having consumed alcohol and three of them presented heavy drinkers behavior. The results indicates the possibility to advance in the evaluation of alcohol use in indigenous populations in Brazil. The improvement of the evaluation created will enable the development of appropriate projects to reduce the losses of alcohol abuse in indigenous communities. Psychology, in a technical and ethical way, must be present in this problematic, important to the biopsychosocial needs of these populations.
\end{abstract}

Keywords: Health Evaluation, Alcoholism, Indigenous Population. 


\title{
Construcción de un Instrumento para Evaluar el Uso de Bebidas Alcohólicas en una Etnia Indígena de Minas Gerais
}

\begin{abstract}
Resumen: El uso abusivo de bebidas alcohólicas es un grave problema de salud pública en indígenas brasileños. El objetivo de este estudio fue desarrollar una entrevista de evaluación que entendiera la frecuencia del uso y los perjuicios del alcohol en esas comunidades, y utilizarla en una evaluación inicial. Esta entrevista de evaluación fue desarrollada a partir de una revisión sistemática de instrumentos ya utilizados nacional e internacionalmente. En el estudio piloto, seis líderes indígenas fueron evaluados por entrevistas individuales, que fueron sometidas al análisis de contenido y categorización de las respuestas. De los indígenas evaluados, todos relataron haber consumido bebida alcohólica, tres presentaron comportamientos de beber mucho y dos reconocieron la necesidad de buscar tratamiento para su consumo de bebida. Los resultados encontrados demuestran que es posible avanzar en la evaluación del uso de alcohol en indígenas en Brasil. El perfeccionamiento de la evaluación desarrollada posibilitará la elaboración de proyectos de intervención adecuados para el enfrentamiento del abuso de alcohol en las comunidades indígenas. La psicología, de forma técnica y ética, debe estar presente en esta problemática, cara a las necesidades biopsicosociales de esas poblaciones.
\end{abstract}

Palabras clave: Evaluación de la Salud, Alcoholismo, Población Indígena.

\section{Introdução}

Estima-se que no Brasil habitem 896 mil pessoas que se declaram ou se consideram indígenas, pertencentes a 215 etnias e falantes de 180 línguas diferentes. Entre os maiores desafios enfrentados por essa população, atualmente, está o abuso de álcool (Oliveira \& Rosa, 2014; Souza, 2013). Ao mesmo tempo, segundo Langdon (2013), há uma escassez de conhecimento acerca da realidade do consumo alcóolico entre os povos indígenas que vivem no território brasileiro. Assim, a investigação detalhada do papel e dos efeitos desencadeados pelas bebidas de alto teor alcoólico entre o povo indígena é necessária (Pena, 2005).

Para acessar e compreender, mesmo parcialmente, o que é uma forma problemática de se beber, é preciso apreender os modos de beber tidos como adequados em cada contexto de atuação. Isso pode ser propiciado pelo conceito de "processos de alcoolização", proposto pelo antropólogo Menendez (1982), ao buscar repensar o conceito de alcoolismo tradicional, redefinindo-o. Para o autor, é preciso atentar-se para as funções e consequências positivas e negativas relacionadas ao uso de álcool em conjuntos sociais estratificados, como é o caso dos povos indígenas. Esse conceito busca o significado que o beber pode assumir em uma dada cultura, viabilizando o acesso às regras e normas que regem o uso do álcool, assim como a respectiva transgressão (Souza, Schweickard \& Garnelo, 2007). Inclui, pois, todos os aspectos envolvidos no beber e evita considerar o problema em termos de enfermidade mental, ressaltando a necessidade de contextualizar a compreensão do uso de álcool nas diferenças individuais, na cultura, na história do indivíduo com a substância e o seu uso problemático ao longo da vida. Assim, a descrição das condições que caracterizam o consumo alcóolico permite entender não só as consequências patológicas, mas a funcionalidade sociocultural do uso do álcool (Menéndez, 2013).

Langdon (2001) recomenda que, ao tratar deste assunto entre povos indígenas, considere-se o olhar sobre o álcool no quando, como, quanto e o que se bebe. Ademais, a avaliação de comportamentos mais relevantes culturalmente, como a frequência e os prejuízos do álcool, deve melhorar a qualidade do cuidado que os indivíduos das minorias étnicas recebem (Blume, Moreira \& La Cruz, 2009). O fenômeno do uso de álcool e drogas é um labirinto de significações que surge de uma complexa vivência e interação entre indivíduos de culturas semelhantes e diferentes, no qual articulam processos de partilha e negociações de significados inseridos numa rede social, histórica e cultural (Conselho Federal de Psicologia, 2013). 
Deve-se considerar, portanto, que tal problemática enfrentada atualmente pelos indígenas possui raízes históricas de dominação sociocultural dos não índios, que deixaram marcas psicossociais que comprometem a qualidade de vida e a saúde mental desses povos (Conselho Regional de Psicologia da 6a Região, 2010). Nesse contexto, surgem tentativas de construir um conhecimento psicológico entre populações indígenas e profissionais da Psicologia. Na publicação "Psicologia e Povos Indígenas" (Conselho Regional de Psicologia da 6a Região, 2010), lideranças indígenas das diversas etnias do Brasil colocam a necessidade do olhar da Psicologia sobre o fenômeno do abuso de álcool. Reforça-se, assim, a atuação do psicólogo na construção de espaços de escuta, de diálogo com horizontalidade e de entendimento dentro da saúde a partir de um olhar diferenciado entre os indígenas e a sociedade, equipes, pesquisadores e gestores não indígenas. Ferraz e Domingues (2016) defendem que o psicólogo, ao entrar em contato com populações indígenas, esteja aberto ao modo como elas compreendem o mundo, permitindo diálogo em que ambas as partes contribuam com seus conhecimentos próprios.

As pesquisas realizadas no Brasil (Souza, 2016) sobre o uso do álcool em populações indígenas com instrumentos psicológicos revelaram a existência de poucos materiais sobre o tema e, especialmente, a inexistência de instrumentos específicos elaborados no cenário nacional. As pesquisas utilizam instrumentos como o CAGE (Souza, Schweickardt \& Garnelo, 2007) e questionários padronizados (Kohatsu, 2001; Souza, 2004). Tais estudos destacam a necessidade de que os instrumentos sejam adaptados para as especificidades locais de cada etnia para melhor utilização destes em cenários culturalmente diferenciados. Para Silva (2013), o grande desafio dos profissionais de saúde é o de prestarem assistência aos povos indígenas transitando no espaço da diversidade cultural expressa por atores que convivem com a dificuldade da comunicação intercultural.

Diante de tal limitação e da necessidade de se avaliar o consumo de álcool, este estudo tem como objetivo desenvolver uma entrevista semiestruturada para avaliação do uso de álcool, que investigue a frequência (uso, abuso e dependência) e os prejuízos (problemas relacionados) do álcool em populações indígenas. Pretende-se, também, realizar uma primeira avaliação deste sistema com lideranças indígenas para investigar sua adequação a uma etnia específica, do estado de Minas Gerais. Este sistema visa estimular a promoção de um diálogo e a abertura de possibilidades entre a comunidade e os profissionais para lidar com os problemas do álcool na terra indígena, gerando impactos nas políticas públicas no campo de atenção à saúde indígena, tendo em vista a redução das consequências negativas que o álcool traz à comunidade.

\section{Método}

\section{Parte I - Desenvolvimento da Entrevista de Avaliação}

\section{Revisão teórica de instrumentos}

Foi realizada uma busca eletrônica de artigos relevantes publicados até fevereiro de 2016, de forma sistematizada (Souza, 2016) nas bases de dados Medline (PubMed), Cochrane Library, PsycoINFO e Lilacs. Os resultados encontraram vinte diferentes instrumentos utilizados para avaliação do uso de álcool em indígenas.

\section{Seleção de parâmetros de avaliação}

Os instrumentos encontrados nos estudos nacionais e internacionais foram analisados segundo os critérios de inclusão (disponibilidade dos instrumentos pelos autores, se avaliavam somente o uso de álcool e se tinham sido aplicados em populações indígenas) e exclusão (não disponível, duplicidade de itens e avaliação de outras drogas) estabelecidos. Dos vinte instrumentos avaliados, cinco foram selecionados: Alcohol Use Disorders Test (AUDIT), questionário, entrevista semiestruturada, CAGE e CAGE-T (Currie et al., 2011; Melo, Maciel, Oliveira, \& Silva, 2010; Saremi et al., 2001; Souza et al, 2007). Após seleção, os itens dos instrumentos foram analisados por especialistas em avaliação psicológica e profissionais com experiências em atuação com povos indígenas. Algumas palavras selecionadas foram adaptadas em uma linguagem compreensível à comunidade abordada.

\section{Elaboração da Entrevista de Avaliação do Uso e Prejuízos de Bebidas Alcóolicas em Indígenas (AUAIN) \\ Com o objetivo de abordar a temática do uso do álcool de maneira clara e evitar possíveis desconfor- tos ou intimidação dos indivíduos, o AUAIN foi cons- truído com perguntas que, partindo da perspectiva histórica, chegam ao uso individual do álcool. Este é constituído por um roteiro de entrevista, elaborado}


para ser aplicado por meio de entrevista semiestruturada e tem como objetivo auxiliar o entrevistador na investigação e no direcionamento das perguntas, com a possibilidade de adotar algumas palavras adaptadas na língua da etnia indígena. Tal modalidade de aplicação visou a liberdade cultural e de expressão dos indí- genas, assim como a possibilidade de acesso às dúvidas de questões colocadas no momento da avaliação e o manejo, pelo profissional de saúde, de possíveis desconfortos gerados durante o processo.

Foram construídas e adaptadas 35 perguntas, divididas em três eixos estruturantes (Tabela). São

Tabela

Entrevista de avaliação.

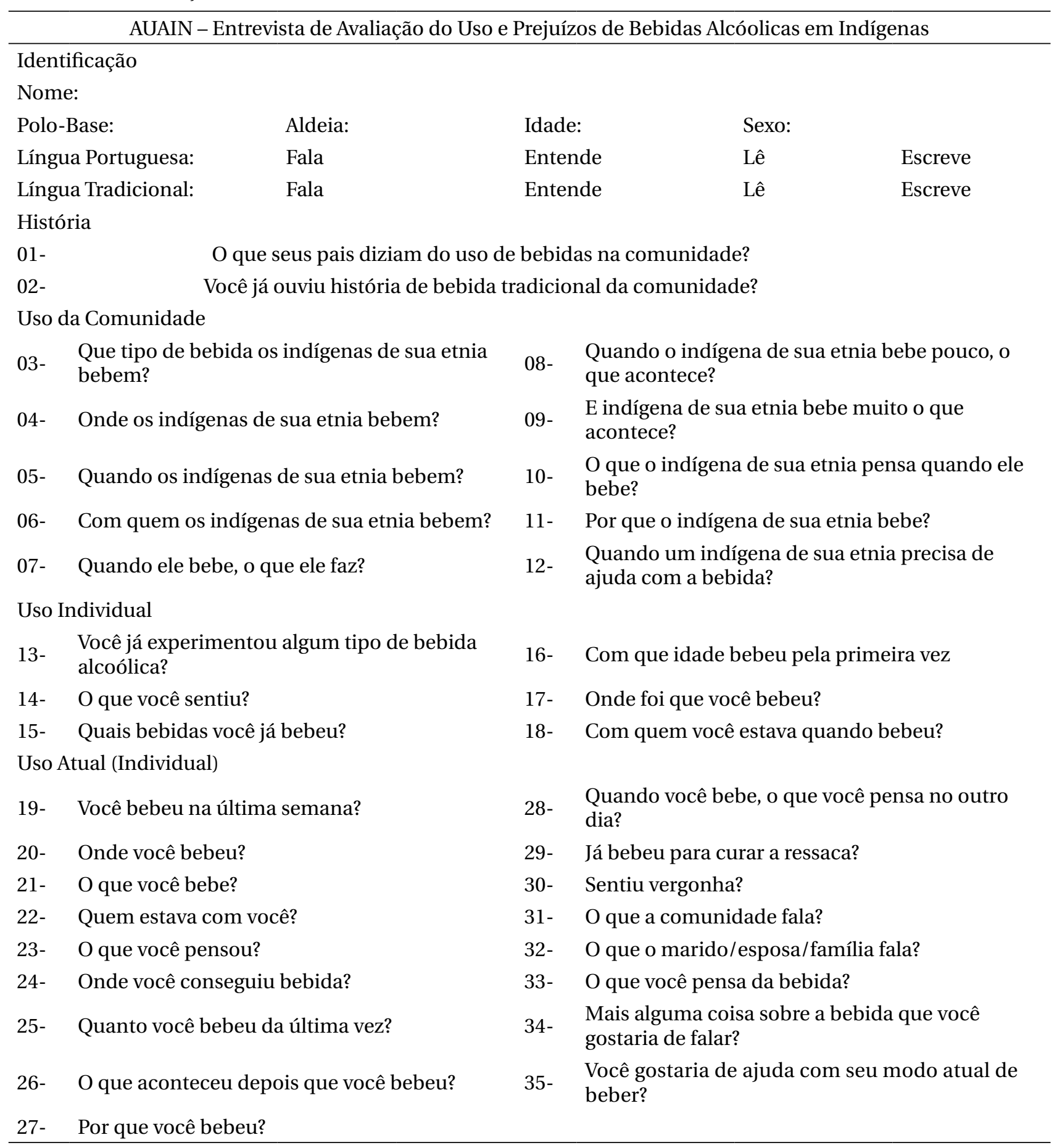


eles: I) Histórias sobre o álcool, que tem como objetivo o resgate de histórias contadas pelos pais e a lembrança de vivências em que o álcool se fez presente na infância ou adolescência, com duas perguntas; II) Uso na comunidade, com dez perguntas que buscam a percepção sobre o beber na aldeia e o consumo de álcool pelos integrantes da comunidade; e III) Uso individual, abrangendo desde o uso atual ou não do indígena, até os prejuízos e tratamento por meio de 23 perguntas.

\section{Parte II - Estudo piloto}

\section{Participantes}

A população da etnia estudada vive em pequenas aldeias dentro de polos-base, cuja distribuição é feita conforme sua organização geo-político-social. Foram selecionados seis indígenas, escolhidos de acordo com o polo-base, com o objetivo de garantir a participação de uma amostra de cada um destes polos. Outro critério utilizado para a seleção foi exercer função de liderança na comunidade e ter compreensão e fluência da língua portuguesa e da língua indígena. Destes seis indígenas selecionados, três eram mulheres e três eram homens com idade média de 47 anos.

\section{Análise dos dados}

Foi realizada a análise de conteúdo das questões contidas no AUAIN. A partir da transcrição das entrevistas, interpretou-se os dados como base nos módulos do instrumento, que se dividem em história do uso, uso coletivo e uso individual. Para a compreensão dos módulos individual e coletivo, adotou-se a análise de categorias formuladas a partir de nove novos blocos (quando, pensamento, quanto, comportamento, tipo, percepção, onde, tratamento, motivação).

A análise de conteúdo foi dividida em duas partes. A primeira consiste em uma análise quantitativa sobre a frequência dos comportamentos relacionados ao álcool no uso coletivo e individual. A segunda, qualitativa, perpassou todos os três eixos da entrevista e seguiu os seguintes passos: análise das falas por perguntas, organização do conteúdo por tema explorado, tabulação segundo o eixo e a descrição segundo as categorias.

\section{Procedimentos éticos}

Foram adotados os procedimentos estabelecidos na resolução do Conselho Nacional de Saúde,
Portaria $\mathrm{n}^{\circ} 466$, de 4 de dezembro de 2012, possuindo número do processo aprovado referente a CAAE: 39170314.4.0000.5149. O projeto foi encaminhado aos seguintes órgãos: Comitê de Ética da Universidade Federal da UFMG (COEP), Comitê Nacional de Ética da Pesquisa (Conep), ao Conselho Nacional de Desenvolvimento Científico e Tecnológico (CNPq), à Fundação Nacional do Índio (Funai) e à Secretaria Especial de Saúde Indígena (Sesai), seguindo as devidas exigências. Houve o preenchimento do Termo de Consentimento Livre Esclarecido (TCLE) pelo participante.

Assegurou-se aos indígenas o sigilo da identidade, o cuidado com as informações prestadas e o respeito às especificidades culturais, linguísticas e à preservação integral do princípio ao respeito à pessoa humana. Optou-se por manter a etnia avaliada no estudo piloto em sigilo, a fim de evitar estigmatização e preconceito com a mesma.

\section{Resultados}

As respostas dadas pelas lideranças indígenas passaram por uma análise quali-quantitativa. Os resultados dessas análises serão apresentados pela divisão acerca do uso coletivo e do uso individual.

\section{Uso coletivo}

O uso coletivo refere-se às respostas sobre a percepção do uso do álcool pela comunidade. A distribuição de respostas dessa categoria apresentou, de modo geral, uma grande variedade de respostas com baixa frequência de citação. As exceções estão no tipo de bebida consumida, na qual cinco lideranças apontam o uso de álcool, cachaça e perfume como presentes na comunidade. Destaca-se, também, a alta frequência sobre o local onde os indígenas mais bebem (cidade) e quando (festas).

De acordo com os entrevistados, os indígenas dessa etnia bebem, geralmente, com parentes - irmão, sogro/sogra, pai, mãe, filho e esposa/esposo - ou amigos. O tipo de bebida mais consumida entre eles varia entre álcool (gel e líquido), misturas (álcool com guaraná, whisky com refrigerante ou água com cachaça), cachaça, perfume, acetona, conhaque (conhaque de gengibre, Presidente ou Deher), cerveja, pinga, vinho, catuaba e whisky.

Os locais de uso mais comuns são a aldeia, as estradas próximas às aldeias, na casa de religião 
(quando homem), nas cidades ao redor, nas fazendas próximas à aldeia ou em "qualquer lugar". A época em que mais se bebe varia entre as festas tradicionais, como apontaram três indígenas, o dia do pagamento e, para dois participantes, não há época, pois "bebem todos os dias". Já a motivação para a procura da bebida são: o vício e a vontade, o costume de gostar de beber, ficar alegre, estar na companhia e na presença dos parentes que bebem, a religião e a vergonha de recusar bebida quando alguém oferece, pois pode receber apelidos pejorativos. Ainda segundo as lideranças, quando os indígenas fazem uso de bebidas, eles tendem a pensar nas histórias antigas, em comprar mais álcool, como indicam três indígenas, ou até mesmo em vender as coisas de casa para se ter mais bebida; brigar com outros, pois se lembram das raivas que têm e, por fim, só pensam na própria bebida.

Os entrevistados relataram que alguns comportamentos frequentes, após ingestão de bebida alcóolica, são: cantar, conversar mais, perder a vergonha, dançar, sair à procura de namorada ou de mais bebida. De acordo com eles, alguns indígenas vão para casa e outros ficam do mesmo jeito, não fazendo nada (sem reação). Além disso, afirmaram que podem ficar mais desinquietos, fracos, alegres, tontos; costumam criar confusão, irritados, "esquentados". Já, quando o uso de álcool é maior, o indígena tende a se deitar e dormir, ficar caído no chão, fazer vômito, ficar procurando mais bebida, conversar muito, ficar alegre até começar a bagunçar, ficar "doido", ficar andando, procurar briga, ter ressaca, bater na família, pensar em parente que já morreu, fazer problema, não se lembrar do que fez, ficar bravo, perder a cabeça e se machucar.

Duas lideranças dizem que o uso de álcool precisa diminuir na aldeia e que a bebida atrapalha a vida na comunidade, impedindo o indígena de trabalhar. Uma delas afirmou, além disso, que as leis, nas cidades próximas às aldeias, precisam ser cumpridas para não ser possível a compra de bebidas, pelos indígenas, com tanta facilidade, pois o álcool gera muita violência; por isso, a comunidade não deve beber. Há, segundo outro entrevistado, indígenas que pedem ajuda para parar de beber, e que, quando se bebe pouco, dá alegria na aldeia, mas, ao beber muito, gera confusão e o indígena perde a consciência; o indígena, quando bebe, não se alimenta e fica vulnerável a doenças. Outrossim, alegou-se, na entrevista de um dos indígenas, que as lideranças devem dar exemplo para a comunidade não beber, e que é preciso investir em educação e saúde com a confecção de materiais para orientação da etnia. Por fim, houve a exposição da necessidade de orientação das gestantes, pois estas usam o álcool, e isso pode gerar consequências aos filhos, como nascer com a dependência de álcool.

Ademais, as lideranças declararam que um indígena precisa de ajuda com a bebida quando o indígena fala que quer morrer, quando não respeita a comunidade gerando brigas e confusão, quando o beber se torna vício com consumo de álcool com maior frequência, e, em concordância, três indígenas alegaram que é quando o indígena não consegue parar de beber. Somente uma das lideranças não descreveu uma forma de detecção de quando um indígena precisa de ajuda quanto ao álcool.

\section{Uso individual}

Nesta etapa, foram computadas todas as referências feitas a qualquer uso de bebida realizada pela liderança durante a sua vida e atualmente. Os resultados demonstram que todos os indígenas entrevistados já experimentaram bebida alcoólica, com maior frequência para o uso da cachaça, sendo mais utilizada junto aos familiares e dentro da aldeia; todos beberam cachaça, três beberam cerveja e três, conhaque. Ressalta-se, também, a frequência do sentimento de vergonha no dia seguinte à ingestão de bebida alcoólica e o interesse por tratamento registrados entre dois entrevistados. Acerca do uso atual, todos responderam que beberam na última semana, só um foi na aldeia e três disseram que beberam pouco.

Dos indivíduos entrevistados, três relataram ter realizado a primeira ingestão de álcool por volta dos 18 anos; um mencionou o primeiro contato com o álcool enquanto era criança, e os outros dois, somente depois de adulto. Estavam presentes, neste primeiro contato, para três indígenas, o pai e a mãe; para dois, o sogro e esposa/esposo; e, para somente um dos entrevistados, amigos.

Quando perguntados se beberam na última semana, os seis entrevistados disseram que sim. Três disseram que beberam na cidade; dois, em uma fazenda próxima à aldeia; e um, na aldeia. Quanto aos locais de fornecimento da bebida, quatro a conseguiram com parentes e dois disseram comprar na venda. Um dos entrevistados destacou que, na roda onde estava, havia a presença de crianças, mas elas não faziam a ingestão da bebida, estavam apenas presentes no ambiente. 
O tipo de bebida mais utilizado no último consumo foi a cerveja, apontada por três deles; dois beberam cachaça; e um disse ter misturado whisky com refrigerante. Neste último consumo, três estavam acompanhados dos parentes, um de amigos e uma do esposo. Os respondentes descreveram que, após a ingestão do álcool, dois foram para casa, dois ficaram dançando, um disse ter ficado muito alegre e outro não achou que ficou diferente permanecendo da mesma forma que estava sem a bebida. Acerca da quantidade de bebida ingerida, na última ocasião, três disseram ter bebido pouco, um disse ter bebido muito e dois não se lembram. Foi descrita a medida que representa o beber pouco e o beber muito para os indígenas dessa etnia. Segundo uma das entrevistadas, essa medida se refere à quantidade de "goladas no tubão" sendo o beber pouco correspondente a uma a três "goladas", e o beber muito refere-se a mais de quatro "goladas". Segundo outra indígena "a gente bebe o que tiver, continuando no outro dia até quando tiver no tubão".

Quando questionados sobre os pensamentos durante o consumo, eles dizem pensar em beber pouco para não tontear, em beber pouco, pois tinham pouco dinheiro; lembram-se da família e, especialmente, que não gostam de beber perto dos filhos. Relataram pensar, também, que consomem a bebida para não chatear os amigos, alegando que "quem não bebe recebe apelidos ruins pelo grupo". Ao serem questionados acerca dos pensamentos no outro dia após a bebida, dois alegaram que acordam pensando em parar de beber, outros dois pensam nos motivos que o/a levaram à bebida e na indisposição física que os/as impede de trabalhar; um pensa na vergonha perante a comunidade e outro disse não pensar em nada no outro dia. Quatro disseram sentir vergonha da família e da comunidade, no outro dia, após beber. Quanto ao comportamento de beber no outro dia para curar a ressaca, somente um indígena relatou essa prática do comportamento, mas fez uma observação de que "bebe não para parar com a ressaca, e sim, para continuar bebendo no outro dia”.

Sobre a percepção da comunidade a respeito do seu beber, duas lideranças disseram que alguns não falam nada, pois bebem também. Dois indígenas reclamaram do comportamento de beber do líder e fazem reunião, pois ficam com vergonha do indígena e até brigam com ele; outros dois alegaram que, mesmo que não bebam, não falam nada. Quanto à percepção da família ou esposa/esposo em relação ao beber, dois relataram que eles não falam nadam pois bebem também; os demais disseram que a família fica com vergonha, ou que a esposa cuida da sua ressaca, ainda, que a família briga por causa do exemplo que este tem que dar à comunidade.

No que diz respeito à opinião deles sobre a bebida na aldeia, uma alegou que medidas precisam ser tomadas para acabar com a bebida, como o cumprimento da lei que regulamenta sua venda nas cidades. Dois disseram que não gostam da bebida na comunidade, pois ela atrapalha a vida na aldeia gerando muita violência, outros dois gostam da bebida para eles, mas não para a comunidade e o último expôs que a bebida impede a comunidade de trabalhar e ter sua cultura. Por fim, quando perguntados acerca da necessidade de ajuda em relação a seu consumo de bebida, dois indígenas disseram que precisam de ajuda para conseguir parar de beber, e os demais relatam que não precisam de ajuda, pois bebem somente em ocasiões específicas.

No final da entrevista, foi acrescentada uma pergunta sobre como medir o consumo de álcool entre os indígenas da etnia, pois, na avaliação da quantidade da última ingestão de álcool, os indígenas demonstraram dificuldade e, muitas vezes, não se lembram da quantidade exata. Duas lideranças sugeriram a apresentação ao indígena de um litro com água, seguida da pergunta sobre a quantidade correspondente no litro de bebida alcoólica por ele ingerida quando bebe. Afirmaram que, na aldeia, os indígenas não utilizam o copo para o consumo de bebida alcoólica, pois eles bebem diretamente no litro ou garrafa, usando a expressão para se referir ao modo de beber com "bebe com a boca no tubão". Três denominaram o recipiente onde se armazena a bebida como "tubão". Um dos indígenas entrevistados não concorda que há como medir o uso de álcool nessa etnia, pois, segundo o entrevistado, não é possível medir a quantidade porque o indígena bebe enquanto tiver no "tubão".

\section{Discussão}

Assim como demonstrado em estudos fora do Brasil (Souza, 2016), o desenvolvimento do AUAIN emerge a discussão acerca da realidade do consumo de álcool nas populações indígenas, ao se abordar a descrição dos seus modos de beber, a identificação das suas particularidades no uso e o conhecimento da atual relação destes com as bebidas de alto teor alcoólico. Nesse con- 
texto, os resultados indicam que é possível avançar na avaliação do uso de álcool em comunidades indígenas brasileiras. Começa-se, dessa forma, a sinalizar o início da superação de uma lacuna nos estudos com populações indígenas no território nacional, que diz respeito ao escasso conhecimento sobre o consumo de álcool dessa população (Langdon, 2013).

Como apontam Diehl e Pellegrini (2014), a dimensão intercultural própria do encontro com indígenas no sistema de saúde evidencia a problemática da adequação ética e cultural de práticas ocidentais para essa população. Porém, diante do já exposto, e como destacado por Souza e Garnelo (2006), a medida é um aspecto importante, ainda que muito delicado, na avaliação do álcool em povos indígenas. Nesse sentido, a entrevista de avaliação desenvolvida avança ao apresentar a possibilidade da medida do álcool. Os indígenas entrevistados reconheceram que mensurar a quantidade que se bebe é difícil, mas não impossível, pois apresentaram duas formas possíveis realizar a medida. A primeira possibilidade de medida é através do uso de exemplos concretos, durante a avaliação, como demonstrar em um litro descartável ("tubão") com água a quantidade que se bebe. Assim, o indígena pode localizar para o entrevistador sua ingestão de bebida. Uma questão surge, diante desta possibilidade, uma vez que a medida para beber entre os povos indígenas tem outras variáveis envolvidas como a oferta e disponibilidade da bebida. Como relatado nas entrevistas, alguns indígenas bebem enquanto tiver no "tubão" - isto representa o consumo do álcool pela acessibilidade e não pela medida. Todavia, foi apresentada uma segunda forma de medir o consumo de álcool: pela via da classificação dos comportamentos de quem bebe muito ou pouco. A primeira classificação - bebe muito - inclui, majoritariamente, comportamentos como brigas, ressaca, fazer vômito, sentir vergonha no dia posterior e perder a cabeça; e o segundo comportamento - bebe pouco - envolve atitudes como ficar alegre, dançar, ir para casa e ficar do mesmo jeito. Portanto, constata-se ser possível conhecer o consumo de álcool por meio dos comportamentos típicos descritos pelos entrevistados.

As descrições destes comportamentos contribuem para os estudos sobre o uso de álcool em povos indígenas (Pena, 2005), pois aponta para a melhor caracterização de reações frente ao consumo de bebida, o que antes não era muito claro. Tugny (2007) demonstrou a existência de expressões xamânicas observadas na expressão dos indígenas após o consumo de álcool. Sobre isso, Fernandes (2013) retoma a história da colonização brasileira para afirmar que as bebidas alcóolicas, antes da chegada dos portugueses, estavam fortemente relacionadas às atividades xamanísticas, mas assumiram uma dimensão catastrófica para as sociedades indígenas com a aproximação europeia. Assim, o presente estudo evidenciou outros comportamentos e reações típicas dos indígenas, o que podem, consoante a relatos dos indivíduos, ser comportamentos disfuncionais à cultura, como as violências e brigas. Pensar na melhor forma de avaliar estes comportamentos é criar uma possibilidade de acessar e poder conhecer melhor o fenômeno.

Acerca disso, o uso de questões do CAGE inseridas no AUAIN demonstra a possibilidade da avaliação de comportamentos dependentes na comunidade, porém, com a necessidade de adaptações, como colocado por Souza e Garnelo (2006). A troca da palavra culpa, no sentido de vergonha, evidencia tal fato. Essa alteração reforça a recomendação da Organização Mundial de Saúde (1993), que, desde o ano de 1996, destaca a importância da adaptação cultural de instrumentos para mensuração do álcool e drogas, com o objetivo de se estabelecer uma "linguagem comum" nessa temática de preocupação mundial. A utilização de questões deste instrumento vai além do encontrado pelos autores Souza e Garnelo (2006), pois, na população avaliada, o uso do CAGE mostra-se favorável, ainda que haja a necessidade da sua utilização em novas pesquisas para a obtenção de outros resultados sobre comportamentos dependentes e as possibilidades de medição do instrumento em populações indígenas.

Em relação aos desafios, destacam-se a compreensão da língua tradicional da etnia avaliada e o entendimento do português. Estes são dois grandes desafios para os trabalhos de avaliação povos indígenas. Porém, estratégias como o uso de expressões e palavras na língua tradicional inseridas no AUAIN tornam a entrevista mais próxima e compreensível, assim como a seleção de indivíduos com maior fluência e entendimento da língua portuguesa. Outra estratégia adotada foi a configuração do instrumento de avaliação como uma entrevista, o que permite ao entrevistador o acesso amplo e profundo do fenômeno, podendo se adaptar às variações do indivíduo e do seu contexto. A condução do estudo por meio de entrevista semi-estruturada 
foi, assim, uma estratégia para se lidar com o limitador da língua, ao assumir, muitas vezes durante o roteiro, expressões na língua tradicional para garantir o entendimento dos indígenas. Ademais, teve como objetivo dar ao entrevistador a possibilidade de manejar e conduzir o processo de forma clara, sendo possível manejar os itens de variadas formas, dentro do mesmo eixo, mudando o modo de perguntar para se alcançar a compreensão do indígena.

\section{Considerações finais}

Tendo em vista algumas dificuldades relatadas por pesquisadores brasileiros ao aplicar instrumentos estruturados, buscou-se criar um roteiro de entrevista semiestruturada. A base para a construção do AUAIN foi instrumentos preconizados pela Organização Mundial de Saúde (1993), como o AUDIT e o CAGE, assim como os modelos de instrumentos internacionais criados segundo as particularidades das populações estudadas. Buscou-se entender, com ele, o uso do álcool a partir da percepção do indígena sobre seu beber, o beber da comunidade e as histórias contadas sobre o álcool. Na construção da entrevista, buscou-se manter as características necessárias para um bom instrumento, como a clareza da linguagem, tendo em vista a população na qual será aplicada, e a pertinência prática, considerando que os itens do instrumento visam avaliar o conceito de interesse da pesquisa (Cassepp-Borges, Baldinotti \& Teodoro, 2010). Cabe ressaltar que o AUAIN foi criado a partir das especificidades de uma etnia, tendo em vista sua língua de origem, a pouca compreensão do português, seus parâmetros de medida e sua forma de compreensão do fenômeno.

Diante dos desafios encontrados e dos avanços possibilitados pelo AUAIN, novas pesquisas e estudos para mensurar o álcool em povos indígenas devem ser realizados, a fim de uma melhor compreensão do instrumento criado e das possibilidades que este pode oferecer para a promoção de saúde indígena, sempre tendo em vista o respeito às suas especificidades culturais.
Com isso, poder-se-á generalizar a entrevista de avaliação criada, para fundamentar intervenções em saúde nas comunidades indígenas, com base em evidências empíricas e com a participação de todos os envolvidos.

A necessidade de tais intervenções é explicitada nos resultados encontrados, que trazem a importância de políticas e estratégias práticas a serem implementadas para minimizar os efeitos negativos que o álcool tem trazido a algumas comunidades tradicionais. Essas intervenções serão possíveis quando as instituições responsáveis pela saúde indígena tiverem disponibilidade e interesse em consolidar parcerias com as universidades, comunidade e os setores públicos, com o intuito de trabalhar projetos de avaliação e intervenção para o enfrentamento do abuso de álcool, que tem gerado consequências devastadoras nas populações indígenas. Muitas vezes, o estigma de índio bêbado e as acusações de "alcoolismo" são usadas por setores políticos da sociedade nacional para justificar a falta de ações, o que demonstra falta de informações e preconceito. Diante disso, é imprescindível que os próprios indígenas façam parte da discussão e da criação de propostas de intervenção. Um diálogo não estigmatizado junto às instituições, municípios e estado, além dos próprios indígenas, tornará possível a efetivação de programas com foco na prevenção de prejuízos causados pelo álcool, em prol da saúde mental indígena.

Portanto, ao passo que a entrevista criada para avaliação do uso de álcool em populações indígenas for aperfeiçoada, projetos de intervenção para avaliar e enfrentar o abuso de álcool nas comunidades indígenas poderão ser elaborados de forma adequada, buscando reduzir os prejuízos advindos desse grave problema da saúde pública. Nesse contexto, é imprescindível que a Psicologia, um dos saberes atuantes da atenção à saúde indígena, de maneira não só técnica, mas ética (Conselho Regional de Psicologia da 6 a Região, 2010), esteja presente e atuante no debate, caro às necessidades biopsicossociais dessas populações.

\section{Referências}

Blume, A. W., Moreira, O. F., \& La Cruz, B. G. (2009). Avaliação dos comportamentos dependentes em culturas das minorias étnicas. In: G. A. Marlatt, \& D. M. Donovan, Avaliação dos comportamentos dependentes (pp. 256-302). São Paulo, SP: Roca.

Cassepp-Borges, V., Balbinotti, M. A. A., \& Teodoro, M. L. M. (2010). Tradução e validação de conteúdo: Uma proposta para a adaptação de instrumentos. In: L. Pasquali, Instrumentação psicológica: Fundamentos e práticas (pp. 506-520). Porto Alegre, RS: Artmed. 
Psicologia: Ciência e Profissão 2019, 39, e176628, 1-11.

Conselho Federal de Psicologia - CFP. (2013). Referências técnicas para a atuação de psicólogas/os em políticas públicas de álcool e outras drogas. Brasília, DF: CFP. Recuperado de http://site.cfp.org.br/wp-content/uploads/2014/01/CREPOP_REFERENCIAS_ALCOOL_E_DROGAS_FINAL_10.01.13.pdf

Conselho Regional de Psicologia da $6^{a}$ Região - CRPSP, (Org). (2010). Psicologia e povos indígenas. São Paulo, SP: CRPSP. Recuperado de http://www.crpsp.org.br/povos/povos/livro.pdf

Currie, C. L., Wild, T. C., Schopflocher, D. P., Laing, L., Veugelers,P. J., Parlee, B. et al (2011). Enculturation and alcohol use problems among aboriginal university students. The Canadian Journal of Psychiatry, 56(12), 735-742. https://doi.org/10.1177/070674371105601205

Diehl, E. E., \& Pellegrini, M. A. (2014). Saúde e povos indígenas no Brasil: O desafio da formação e educação permanente de trabalhadores para atuação em contextos interculturais. Caderno de Saúde Pública, 30(4), 867-874. https://doi.org/10.1590/0102-311X00030014

Fernandes, J. A. (2013). Cauinagens e bebedeiras: os índios e o álcool na história do Brasil. In: M. L. P. Souza (Org.), Processos de alcoolização indígena no Brasil: Perspectivas plurais. (pp. 27-46). Rio de Janeiro, RJ: Fiocruz.

Ferraz, I. T. \& Domingues, E. (2016). A psicologia brasileira e os povos indígenas. Psicologia: Ciência e Profissão, 36(3), 682-695. https://doi.org/10.1590/1982-3703001622014

Kohatsu, M. O. (2001). Alcoolismo na comunidade Kaingang de Londrina. In: Seminário sobre alcoolismo e DST/ AIDS entre povos indígenas (pp 189-195). Brasília, DF: Ministério da Saúde.

Langdon, E. J. M. (2001). O que beber, como beber e quando beber: O contexto sociocultural no alcoolismo entre as populações indígenas. In: Seminário sobre alcoolismo e DST/AIDS entre os povos indígenas (pp. 83-97). Brasília, DF: Ministério da Saúde.

Langdon, E. J. M. (2013). O abuso de álcool entre os povos indígenas no Brasil: Uma avaliação comparativa. In: M. L. P. Souza (Org.), Processos de alcoolização indígena no Brasil: Perspectivas plurais (pp. 27-46). Rio de Janeiro, RJ: Fiocruz.

Melo, J. R. F., Maciel, S. C., Oliveira, R. C. C., \& Silva, A. O. (2010). Implications of alcohol abuse and consumption in the potiguara indigenous community. Physis Revista de Saúde Coletiva, 21(1), 319-333. https://doi.org/10.1590/ S0103-73312011000100019

Menendez, E. L. (1982) El proceso de alcoholizacion: revision critica de la producion socioantropologica, histórica y biomédica en America Latina. Cuaderno de la Casa Chata, 57, 61-94.

Menéndez, E. L. (2013). Prefácio. In: M. L. P. Souza (Org.), Processos de alcoolização indígena no Brasil: Perspectivas plurais (pp 11-15). Rio de Janeiro, RJ: Fiocruz.

Oliveira, R. N. C., \& Rosa, L. C. S. R. (2014) Saúde indígena em tempos de barbárie: Política pública, cenários e perspectivas. Revista de Política Pública, 18(2), 481-496. https://doi.org/10.18764/2178-2865.v18n2p481-496

Organização Mundial de Saúde - OMS. (1993). Classificação de transtornos mentais e de comportamento da CID-10. Porto Alegre, RS: Artes Médicas.

Pena, J. L. (2005). Os índios Maxakali: A propósito do consumo de bebidas de alto teor alcoólico. Revista de Estudos e Pesquisas FUNAI, 2(2), 99-121.

Saremi, A., Hanson, R. L., Williams, D. E., Roumain, J., Robin, R.W. et al (2001).Validity of the CAGE questionnaire in an American Indian population. Journal of Studies on Alcohol and Drugs, 62(3), 294-300. https://doi.org/10.15288/jsa.2001.62.294

Silva, C. B. (2013). Profissionais de saúde em contexto indígena: Os desafios para uma atuação intercultural e dialógica. ANTROPOS Revista de antropologia, 5(6), 3-36.

Souza, M. L. P. (2004). Alcoolização e violência no alto rio negro (Dissertação Mestrado). Universidade Federal do Amazonas, Manaus, AM, Brasil.

Souza, M. L. P. (2013). Processos de alcoolização indígena no Brasil: Perspectivas plurais. Rio de Janeiro, RJ: Fiocruz.

Souza, M. L. P., \& Garnelo, L. (2006). Desconstruindo o alcoolismo: Notas a partir da construção do objeto de pesquisa no contexto da saúde indígena. Revista Latinoamericana de Psicopatologia Fundamental, 9(2), 279-292. https://doi.org/10.1590/1415-47142006002007

Souza, M. L. P., Schweickard, J. C., \& Garnelo, L. (2007). O processo de alcoolização em populações indígenas do Alto Rio Negro e as limitações do CAGE como instrumento de screening para dependência ao álcool. Revista de Psiquiatria Clínica, 34(2), 90-96. https://doi.org/10.1590/S0101-60832007000200005 
Souza, S. B. (2016). Avaliação do uso de álcool no povo indígena Maxakali. (Dissertação de mestrado). Universidade Federal de Minas Gerais, Belo Horizonte, MG, Brasil.

Tugny, R. P. A. (2007). Relatório parcial do plano de ação em saúde para o povo Maxakali (Mimeografado). Belo Horizonte, MG.

\section{Ronaldo Santhiago Bonfim de Souza}

Mestre pelo Programa de Pós-Graduação em Psicologia, Faculdade de Filosofia e Ciências Humanas da Universidade Federal de Minas Gerais, Belo Horizonte - MG. Brasil.

E-mail: santhiagosouza@yahoo.com.br

(iD) http://orcid.org/0000-0001-8543-6935

\section{Júlia Costa de Oliveira}

Graduanda em Psicologia pela Universidade Federal de Minas Gerais, Belo Horizonte - MG. Brasil.

E-mail:co.julia@hotmail.com

(iD) http://orcid.org/0000-0003-3899-1092

\section{Maycoln Leôni Martins Teodoro}

Professor do Programa de Pós-Graduação em Psicologia, Faculdade de Filosofia e Ciências Humanas da Universidade Federal de Minas Gerais, Belo Horizonte - MG. Brasil.

E-mail: mlmteodoro@hotmail.com

(iD) http://orcid.org/0000-0002-3021-8567

Endereço para envio de correspondência:

Avenida Antônio Carlos, 6627, Pampulha. CEP: 31270-901.

Belo Horizonte - MG. Brasil.

Recebido 05/03/2017

Reformulado 13/09/2017

Aceito 13/11/2017

Received 03/05/2017

Reformulated $09 / 13 / 2017$

Approved 11/13/2017

Recibido 05/03/2017

Reformulado 13/09/2017

Aceptado 13/11/2017

Como citar: Souza, R. S. B.; Oliveira, J. C.; Teodoro, M. L. M. (2019).Construção de um Instrumento para Avaliar o Uso de Bebidas Alcóolicas em uma Etnia Indígena de Minas Gerais. Psicologia: Ciência e Profissão, 39, 1-11. https://doi.org/10.1590/1982-3703003176628

How to cite: Souza, R. S. B.; Oliveira, J. C.; Teodoro, M. L. M. (2019).Construction of an Instrument to Evaluate the Use of Alcoholic Beverages in an Indigenous Ethnic Group of Minas Gerais. Psicologia: Ciência e Profissão, 39, 1-11. https://doi.org/10.1590/1982-3703003176628

Cómo citar: Souza, R. S. B.; Oliveira, J. C.; Teodoro, M. L. M. (2019). Construcción de un Instrumento para Evaluar el uso de Bebidas Alcohólicas en una Etnia Indígena de Minas Gerais. Psicologia: Ciência e Profissão, 39, 1-11. https://doi.org/10.1590/1982-3703003176628 